\title{
A PRESENÇA DA TEMÁTICA SOCIOAMBIENTAL NOS TCCS DO CURSO DE CIÊNCIAS BIOLÓGICAS DA UNOCHAPECÓ
}

\author{
Ingridy Manila Colpani ${ }^{1}$; Ivo Dickmann ${ }^{2}$ : Luciane da Rosa $^{3}$; Larissa Henrique ${ }^{4}$
}

\section{RESUMO}

Este artigo analisou se dentro do curso de Ciências Biológicas da Universidade Comunitária da Região de Chapecó - Unochapecó, estão sendo abordados, nos trabalhos de conclusão de curso, temas referentes à temática socioambiental. Com isso, verificou-se em quais correntes de Educação Ambiental estes trabalhos se enquadram. Como metodologia utilizou-se a análise de conteúdo, tendo como base teórica o legado de Freire referente à relação ser humano e mundo, o seu papel em sociedade e sua capacidade de transformação da realidade-ambiente. Conclui-se que há uma inegável importância da formação dos educadores para o ensinamento do conhecimento em Educação Ambiental e que o curso de Ciências Biológicas tem fomentado uma diversidade de estudos socioambientais distribuídos em diversas correntes de Educação Ambiental.

Palavras-chave: Formação de Professores, Educação Ambiental, Ciências Biológicas.

\begin{abstract}
This article analyzes if within the course of Biological Sciences of the Community University of the Region of Chapecó - Unochapecó, topics related to social-environmental issues are being discussed in the course conclusion works. With this, it was verified in which currents of Environmental Education these works fit. As a methodology, content analysis was used, based on Freire's legacy concerning the relationship between human beings and the world, their role in society and their capacity to transform reality and environment. It is concluded that there is an undeniable importance of the training of educators for the teaching of knowledge in Environmental Education and that the course of Biological Sciences has fostered a diversity of socio-environmental studies distributed in several streams of Environmental Education.
\end{abstract}

Keywords: Teacher Training, Environmental Education, Biological Sciences.

\section{INTRODUÇÃO}

Terremotos, enchentes, tempestades, alterações climáticas, enfim, os desastres naturais e as modificações que estão ocorrendo em nosso planeta, são alguns dos temas mais comentados atualmente. Vemos a força da natureza e sabemos que estamos à beira

\footnotetext{
${ }^{1}$ Graduada em Ciências Biológicas - Unochapecó, membro do Palavração- Grupo de Estudos, Pesquisa e Documentação em Educação Ambiental Freiriana.

${ }^{2}$ Pós-doutorando em Educação, Doutor e Mestre em Educação, Graduado em Filosofia, professor do Mestrado em Educação da Unochapecó. Líder do Palavração - Grupo de Estudos, Pesquisa e Documentação em Educação Ambiental Freiriana.

${ }^{3}$ Mestranda em Educação na Unochapecó, Graduada em Ciências Biológicas. Membro do PalavraçãoGrupo de Estudos, Pesquisa e Documentação em Educação Ambiental Freiriana.

${ }^{4}$ Graduanda em Pedagogia pela Unochapecó. Bolsista de Iniciação Científica no Projeto Sementes na Terra - Educação Ambiental e Agricultura Familiar. Membro do Palavração- Grupo de Estudos, Pesquisa e Documentação em Educação Ambiental Freiriana.
} 
de um caos. Nossas atitudes em relação ao planeta são o que definem a velocidade com que esses fenômenos ocorrem. Sabemos que só vamos conseguir reverter essa situação e ter mais qualidade de vida quando todos tomarem uma posição diante da natureza e repensarem suas atitudes. Para que isso aconteça é necessário ter consciência sobre os impactos que causamos no meio ambiente.

Devido a estes acontecimentos, se faz necessário o estudo e desenvolvimento de meios sustentáveis de vida, para assim, evitar maiores impactos possíveis ao meio ambiente, com um consumo consciente e equilibrado dos bens naturais renováveis e não renováveis. Cada vez mais, se tem pensado na necessidade de agir, pensando na conservação do meio ambiente, e isto está acontecendo devido a sinalização que a natureza está nos dando ao longo dos anos.

Tendo essa perspectiva como referência, este estudo constituiu-se como uma abordagem dos trabalhos de conclusão de curso (TCCs) de Ciências Biológicas que se referem à Educação Ambiental que tem como tema central as questões socioambientais, especialmente as referentes à relação ser humano e mundo. Nesse estudo tomaremos como referência a perspectiva de Paulo Freire, descrita por Dickmann e Carneiro (2012), que nos traduz o processo de reconhecimento do ser humano como parte integrante do mundo e contribuições freirianas para uma educação ambiental crítica.

Partindo do pressuposto que a pesquisa é um ato pedagógico constante na formação inicial dos educadores que depois vão trabalhar na escola e que está ligada a diferentes abordagens teórico-metodológicas (ROMÃO, 2005), mas que se configuram como pesquisa em educação em suas diferentes concepções (STRECK, 2015), buscaremos conhecer melhor o que foi produzido de conhecimento científico, através dos TCCs, para classificar e refletir sobre essa produção em educação ambiental.

O debate ambiental compõe os temas transversais dos Parâmetros Curriculares Nacionais, pois são considerados componentes para uma formação crítica e emancipatória (DICKMANN; HENRIQUE, 2016), sendo assim só haverá avanços na realidade ambiental quando a construção dos currículos traduzirem as concepções, os conhecimentos, as culturas e valores de que são produtores e sujeitos os movimentos sociais (ARROYO, 2015).

Para Dickmann e Henrique (2017) é na universidade que ocorre a formação dos educadores ambientais, sendo de muita importância, pois precisamos de profissionais comprometidos com a transformação da realidade, para atender as necessidades 
ambientais. O Curso de licenciatura em Ciência Biológicas da Unochapecó tem seu foco de pesquisa e extensão direcionado para a área de atuação dos professores, no ensino de Ciências e Biologia, e possui desde sua gênese a formação de um educador ético, reflexivo e crítico, que seja capaz de analisar as questões educacionais e propor soluções aos problemas relacionados à sua área de atuação (UNOCHAPECÓ, 2016a).

Diante disso, o problema que se propôs essa pesquisa era saber se os TCCs da licenciatura em Ciência Biológicas estão orientados para pesquisar as questões relativas a temática socioambiental e, desse modo, visou-se estabelecer em quais correntes de Educação Ambiental eles se enquadram. Para tanto, o objetivo geral foi: Analisar os TCCs defendidos na licenciatura de Ciências Biológicas da Unochapecó, que contemplem as temáticas da Educação Ambiental. E estabeleceram-se dois objetivos específicos:1) Mapear as correntes de Educação Ambiental nos TCCs da licenciatura; 2)Refletir sobre a inserção do tema Educação Ambiental dentro do currículo do Curso de Ciências Biológicas da Unochapecó.

Permanentemente o curso de Ciências Biológicas se preocupa com as modificações que ocorrem na natureza e que se intensificaram a partir da intervenção do ser humano, o processo de degradação se confunde com esse momento. Na maior parte da história, o homem acreditou que seria cobrado por aquilo que fizesse contra a natureza, assim retirando somente o necessário para seu sustento, mas com o passar do tempo, principalmente a partir das Idades Média e Moderna o ser humano começou a agredir fortemente o meio ambiente (SPAREMBERGER; SILVA, 2005).

Entretanto, a dinâmica da urbanização tem provocado um aumento dos problemas ambientais nas nossas cidades. Embora todos sejam afetados pelos problemas, os setores mais carentes da população sofrem mais (BRAYNER, 1996).

O apontamento das correntes da Educação Ambiental exploradas nas TCCs, se justifica, pelo conhecimento dos discursos pregados por cada uma destas correntes, pois, independentemente da sua preocupação com o meio ambiente, cada uma vem exaltando seu modelo ou método.

Este trabalho contribui para refletir a importância do meio ambiente, para a existência dos seres humanos, fato este, que para muitos é irrelevante em suas atitudes no dia a dia; esta importância, pode ser justificada por Sauvé (2005b, p. 317), a seguir: 
obriga um desenvolvimento que desejamos seja sustentável. A trama do meio ambiente é a trama da própria vida, ali onde se encontram natureza e cultura; o meio ambiente é o cadinho em que se forjam nossa identidade, nossas relações com os outros, nosso "ser-no-mundo".

Com isso, podemos também justificar este estudo, pela importância da exploração e inclusão do tema Educação Ambiental nos currículos dos cursos de Ciências Biológicas, especialmente da licenciatura que forma os profissionais para a Educação Básica. A preocupação com a educação deste texto refere-se como afirmam Höeffel et al (1998, p. 24):

Educação - diz respeito ao caráter formativo do ser humano, promovendo uma postura interna de reverência pela vida, formando pessoas amorosas, ressaltando a importância do autoconhecimento, da inclusão de outros seres nos processos individuais e da expansão para o coletivo. A caracterização destes elementos parte de uma revisão conceitual que resgata e amplia a cosmovisão de diferentes culturas, que concebem a vida como unidade, e enfatizam a necessidade de despertar o ser humano para o sentir, pensar e agir, conscientes e comprometimentos com o desenvolvimento da humanidade.

Ruth Rocha (1996 apud OLIVEIRA, 2016), diz que a educação é o "ato de educar; ensino; processo pelo qual uma função se desenvolve e se aperfeiçoa pelo próprio exercício". Sendo assim, descrevemos a relevância deste estudo, para que possa ser colocado em prática os atos descritos acima, principalmente dentro do tema Educação Ambiental, que é de extrema importância para a qualidade de vida de todo o ecossistema. Isso nos permitirá entender quais as correntes de Educação Ambiental estão presentes nos TCCs dos acadêmicos, reconhecendo e organizando os trabalhos a partir das abordagens, tanto na linha das tendências tradicionais, preservacionistas e conservacionistas quanto de uma Educação Ambiental emancipatória.

\section{REVISÃO BIBLIOGRÁFICA}

\section{Relação Ser Humano e Meio Ambiente}

A formulação a respeito do conceito de meio ambiente, considerada uma das mais bem elaboradas e mais críticas a respeito do tema é descrita por Reigota (1995, p. 14):

Defino meio ambiente como o lugar determinado ou percebido, onde os elementos naturais e sociais estão em relações dinâmicas e em interação. Essas relações implicam processo de criação cultural e tecnológica e processos históricos e sociais de transformações do meio natural e construído. 
Cada dia mais a humanidade vêm desenvolvendo uma consciência ecológica em relação à proteção do meio ambiente (SPAREMBERGER; SILVA, 2005). Esta conscientização, seria ideologicamente e teoricamente correta e sustentável, porém, na prática com maior parte da humanidade não é o que ocorre. A existência desta consciência ecológica surge para o ser humano quando ele próprio se reconhece como parte integrante do ambiente, do planeta, do mundo, visto que são seus atos que determinam algumas das repostas que a natureza vem nos trazendo ao longo da história. Respostas estas descritas através das notícias diárias a respeito de desastres ambientais e climáticos. Segundo Dickmann e Carneiro (2012, p. 93) a concepção de mundo de Paulo Freire nos ajuda a compreender esse pertencimento:

\begin{abstract}
Quanto à concepção de mundo, para Freire o mundo é lugar da presença humana, ou seja, uma realidade objetiva que engloba tanto o mundo natural biofísico quanto o mundo cultural e dos quais o ser humano faz parte, pelos seus aspectos biológicos e pelo seu poder criador. [...] o mundo não é apenas suporte natural para a vida, mas o lugar onde o ser humano faz história e faz cultura. [...] o mundo é lugar da existência das relações, das interdependências, tanto entre os seres humanos como destes com o mundo.
\end{abstract}

O reconhecimento do mundo na concepção de Freire, acima de tudo é um lugar onde o ser humano constrói-se como ser histórico e cultural. As relações que ligam o ser humano ao mundo, na grande maioria se dão em torno do capitalismo e consumismo, sem pensar nas consequências de suas atitudes, de seu modo de produção e consumo. Parte-se do princípio das relações sustentáveis dos seres humanos entre si e com o mundo para garantir a qualidade de vida de todos os seres, das atuais e futuras gerações, o que gera uma atenção para não agredir o meio ambiente.

Freire focaliza o ser humano como ser relacional, intimamente ligado com o mundo e o coloca como consciência do mundo e de si, o que implica a sua responsabilidade ética para com a realidade-ambiente. Tal concepção de mundo é de importância constitutiva na Educação Ambiental, no sentido de fundar e possibilitar a reflexão desveladora das relações entre o ser humano e o mundo - aspecto central a uma educação voltada ao meio ambiente (DICKMANN; CARNEIRO, 2012, p. 93).

Reconhecer a importância do mundo, e dos seres humanos, como parte integrante dele, leva ao entendimento relacional entre meio ambiente e ser humano, frente a realidade concreta. Este cenário inter-relacional mostra que através da educação, o ser humano pode chegar ao reconhecimento do seu papel em relação no mundo, e isso só será possível se ele reconhecer que suas atitudes refletem e são as responsáveis pela qualidade de vida. Pois, bem se sabe, que 
principalmente em países desenvolvidos falar em um desenvolvimento sustentável, onde se pense em agredir menos possível o meio ambiente significa em maior parte, desacelerar seu crescimento, pois implicaria na mudança radical do seu modo de produção e consumo, sem pensar nos efeitos catastróficos que podem ocorrer para as próximas gerações.

\begin{abstract}
Destruímos constantemente a natureza, pois a consumimos, lutamos pela manutenção de equilíbrios, articulamos lutas de emancipação, deslocamo-nos vigência de outros ritmos, produzimos nos tempos da pós-modernidade. Somos o resultado e os produtores de tudo que se dá ao nosso redor. Paradoxo fundamental da própria existência humana: lutar pela vida que, inexorável, caminha para a morte! (CASCINO, 1998, p. 17).
\end{abstract}

Dickmann e Carneiro (2012, p. 92), colocam que “[...] na visão de Freire, o ser humano enquanto ser relacional, com o mundo e no mundo - um ser-em-comunicação. É nessa comunicação dialógica que ele vai fazendo a história e a cultura, vai transformando o mundo e a si mesmo [...]", através desta comunicação o ser humano vai à busca de respostas e soluções. Esta dialógica é importante e fundamental na educação, onde pode haver reflexões conectando os problemas ambientais à realidade cultural e social de cada povo.

\title{
Educação Ambiental
}

A história da Educação Ambiental se confunde com a preocupação em preservar parte da natureza como uma necessidade para salvar o planeta, que começa nos Estados Unidos no século XIX com os parques nacionais. Surge daí o que foi chamado por Diegues (2001) de mito da natureza intocada, dentro de uma perspectiva preservacionista e recursista de meio ambiente. Dentro deste histórico é importante ressaltar o papel do movimento ambientalista, as conferências internacionais sobre o meio ambiente da ONU (Organização as Nações Unidas) em que se destacam a de Estocolmo (1972), de Tbilisi (1977) e a do Rio de Janeiro (RIO-92), de onde surge a Agenda 21 e o Tratado das Sociedades Sustentáveis e Responsabilidade Global.

Sabiá (1998, p. 35), também contribui a respeito da interação do homem perante a natureza, dizendo que: "A Educação Ambiental configura-se como importante instrumento de promoção da consciência ambiental e estratégia fundamental para se conseguir criar e aplicar formas mais eficazes e sustentáveis de integração 
sociedade/natureza [...]", ou seja, promovendo a disseminação da Educação Ambiental, teremos um sujeito mais consciente do seu papel perante a natureza.

Exalta-se a importância nos dias de hoje, a discussão e inserção do tema Educação Ambiental, principalmente nos meios escolares em todos os níveis de ensino, pois é um tema de grande relevância para o presente e o futuro de nosso planeta. A produção de conhecimento se dá em maior parte nos meios escolares e acadêmicos, onde se gera discussões e se busca alternativas para melhor desenvolver suas ideias e conhecimento a respeito de um tema, principalmente sobre Educação Ambiental, gerando melhor qualidade de vida, e o educador ambiental precisa estar preparado desde sua formação inicial para trabalhar em sala de aula as questões relativas ao meio ambiente.educador assume importante papel ao atuar como coordenador de atividades integradas dentro e fora da sala de aula, liderando, monitorando e incentivando a percepção, a criatividade, a análise crítica das causas e consequências ambientais e as sugestões de soluções (SABIÁ, 1998, p. 36).

A importância da Educação Ambiental e da formação de educadores ambientais, não se dá somente para o currículo dos Cursos de Ciências Biológicas, mas sim, é um instrumento que deve ser introduzido a todos os setores da sociedade. Segundo Jacobi (1998, p.15) é importante:

\footnotetext{
Educar crianças, educar jovens, educar. Mais do que tarefa, mais que uma missão, trabalho, dedicação. Criar planos de ação, considerar conceitos, teorias, reflexões, interações entre desejo, a necessidade e a possibilidade, usar o bom senso, o senso de limites, repensar os espaços e as tarefas educacionais formais e não formais, enfim, repensar currículos.
}

Como demonstrado em estudo de Iared et al. (2011), o tema Educação Ambiental em seu conteúdo nas diferentes matérias, não é abordado a partir de uma única fundamentação teórico-metodológica e orientação político-ideológica, considerando o conjunto das disciplinas, sendo que, muitos aspectos importantes a respeito da questão ambiental deixam de ser contemplados.

Apesar da carência de conteúdo explorado sobre o tema em escolas, cabe destacar a importância do tema, e as contribuições que a introdução da Educação Ambiental nos currículos escolares, em relação a formação dos sujeitos-alunos.

Ainda, se pode trazer a contribuição dada por Cascino (1998), a respeito das discussões geradas a partir do tema Educação Ambiental, onde demonstra a universalização da preocupação com o meio ambiente, onde se tem gerado grandes 
frentes de estudo e pesquisa, para se encontrar meios de um desenvolvimento com menor agressão ao planeta.

\begin{abstract}
A Educação Ambiental, gestada a partir dos grandes debates sobre o futuro do planeta e o papel que desempenha as novas gerações na manutenção e uso sustentável dos recursos naturais, vêm assumindo importante papel na consolidação de uma linguagem comum, coletivizada, sobre questões ambientais, organismos internacionais, os mais variados grupos de interesses e as representações relativamente articuladas (CASCINO, 1998, p. 15).
\end{abstract}

Segundo Sauvé (2005b, p. 317): "A educação ambiental não é, portanto, uma "forma" de educação (uma educação para...) entre inúmeras outras; não é simplesmente uma "ferramenta" para a resolução de problemas ou de gestão do meio ambiente", mais do que uma educação "a respeito do, para o, no, pelo ou em prol do" meio ambiente, o objeto da educação ambiental é de fato, fundamentalmente, nossa relação com o meio ambiente. Para intervir de modo mais apropriado, o educador deve levar em conta as múltiplas facetas dessa relação, que correspondem a modos diversos e complementares de apreender o meio ambiente.

Estes modos de apreender o meio ambiente são descritos como o Meio Ambiente Natureza, Meio Ambiente Recurso, Meio Ambiente Problema, Meio Ambiente Sistema, Meio Ambiente Lugar em que se Vive, Meio Ambiente Biosfera, Meio Ambiente Projeto Comunitário, Meio Ambiente Território, Meio Ambiente Paisagem (SAUVÉ, 2005b). Ainda, coloca que outras representações do meio ambiente podem ser identificadas e caracterizadas além dessa que ela organizou. Sobre como deve se desenvolver a Educação Ambiental em relação a estas representações, Sauvé (2005b, p. 319), diz que "Uma educação ambiental limitada a uma ou outra dessas dimensões fica incompleta e alimenta uma visão enviesada do que seja "estar-nomundo"".

Devido à valorização expressa à natureza, por meio de ações que estão sendo introduzidas na sociedade, através da Educação Ambiental nas suas diversas correntes, buscou-se compreender maneiras as quais este tema foi, está e poderá estar sendo introduzido nos diversos meios da educação e sociedade em geral, bem como nos TCCs, objeto dessa pesquisa. Para chegar a este entendimento, fez-se uso das percepções referentes ao meio ambiente e mundo feitas por Freire, em relação ao conhecimento e reconhecimento desses pelo ser humano, que estão descritas a seguir por Dickmann (2016, p. 12-13): 
Na verdade, Freire inicialmente tinha a percepção que ao conhecer o mundo as pessoas imediatamente se mobilizariam em torno de sua mudança, sendo que mais tarde ele admite que não basta conhecer, mas é preciso organizar-se para uma intervenção qualificada e transformadora, libertadora. Em resumo, a concepção freiriana de conhecimento de mundo, ligado ao processo educativo, descobre que se a educação mantém a sociedade, é porque pode transformar aquilo que mantém - surge aí a tarefa político-pedagógica da educação [...].

Dickmann (2016, p. 13), nos coloca ainda que na visão de Freire “[...] conhecer o mundo é um processo em que a percepção que temos da realidade está conectada ao contexto que estamos inseridos, nosso cotidiano [...] que vão contribuir para a transição da consciência ingênua para a consciência crítica [...]”, ele reforça ainda, em relação a estes fatores que "podem favorecer um processo de estagnação do processo da conscientização, em que a percepção de mundo, em vista da transformação se anestesia, gerando uma percepção neutra da totalidade do real". A respeito do real, Dickmann (2016, p. 13), chama a atenção:

[...] a percepção do real encontra seu termo na comunicação, na interação no saber-pensar-agir crítico dos seres humanos em suas comunidades de vivência, em vista da construção de melhor qualidade de vida para todos - o que implica na crítica ao atual modo de produção e consumo insustentável que rege o nosso modelo de vida hodierno. Por isso conhecer a realidade em seus diversos aspectos é um trabalho árduo que tem duração cotidiana em nossa passagem nesse planeta [...].

Para desenvolver este estudo, buscou-se estar ciente da realidade sobre o tema, para poder considerar as diversas correntes defendidas dentro da educação ambiental, e o que elas trazem de conscientização referente ao estudo da educação ambiental dentro e fora dos meios de ensino, pois, como colocado por Dickmann (2016, p. 14), “[...], a criticidade não se desenvolve num só lugar e de forma linear [...]”, ainda contribui dizendo que, "[...] cada ser humano desenvolve uma caminhada de conscientização diferente, que vai a múltiplas direções, mas que podem findar no mesmo ponto, embora trilhem caminhos distintos".

Freire vem sendo referenciado por muitos pesquisadores como base de estudo da Educação Ambiental, o que justifica isto é a própria história de vida de Freire com a realidade brasileira (LOUREIRO, 2009). Dickmann (2016, p. 19) justifica utilizar a percepção de Freire em relação ao mundo e meio ambiente: 
processos educativos, que se estabelece a partir das dimensões ético-políticas, técnico-científicas, epistemológicas, estético-afetivas e pedagógicas [...].

\title{
Correntes da Educação Ambiental
}

O tema Educação Ambiental abrange muitas correntes, as quais são defendidas por seus idealizadores; a seguir será tratada uma concepção a respeito da Educação Ambiental.

\begin{abstract}
Trata-se de uma dimensão essencial da educação fundamental que diz respeito a uma esfera de interações que está na base do desenvolvimento pessoal e social: a da relação com o meio em que vivemos, com essa "casa de vida" compartilhada. A educação ambiental visa a induzir dinâmicas sociais, de início na comunidade local e, posteriormente, em redes mais amplas de solidariedade, promovendo a abordagem colaborativa e crítica das realidades socioambientais e uma compreensão autônoma e criativa dos problemas que se apresentam e das soluções possíveis para eles (SAUVÉ, 2005b, p. 317).
\end{abstract}

A seguir são demonstradas as quinze correntes de Educação Ambiental que tem como base a cartografia elaborada por Sauvé (2005a), sendo que a respeito destas, a autora afirma que: "A noção de corrente se refere aqui a uma maneira geral de conceber e de praticar a educação ambiental. Podem se incorporar, a uma mesma corrente, uma pluralidade e uma diversidade de proposições". A seguir são apresentadas cada uma destas correntes:

Naturalista: é centrada na relação com a natureza, com enfoque cognitivo, aprender coisas sobre a natureza de forma afetivo-espiritual e artístico;

Conservacionista/Recursista: preocupa-se com a conservação dos recursos naturais, entendendo-os como bens escassos, tais como a água, o solo, a energia, as plantas e os animais, entre outros; ao falar de conservação entende a natureza como recurso, focado na gestão ambiental centrada na estratégia dos 3R (reduzir, reutilizar, reciclar).

Resolutiva: toma o meio ambiente como um conjunto de problemas, buscando solucioná-los, tendo sua origem no programa internacional da UNESCO para a educação ambiental.

Científica: o meio ambiente é objeto de conhecimento, associa-se ao desenvolvimento de habilidades relativas às ciências ambientais, de pesquisa interdisciplinar para o transdisciplinar. Esta corrente tem como objetivo buscar a comprovação através da elaboração de hipóteses e métodos. 
Holística: é uma tentativa de transpor o enfoque meramente racionalista das questões ambientais, que estão na base dos grandes desastres atuais, considerando um conjunto de múltiplas dimensões da realidade socioambiental em sua complexidade.

Biorregionalista: inspira-se numa ética ecocêntrica, focada na relação referenciada no local ou regional, na construção do sentimento de pertencimento e valorização do meio.

Práxica: visa mudança do meio através de reflexões e ações de trocas positivas, tem ênfase na aprendizagem, na ação e na melhora dessa ação para mudar o ambiente, é uma reflexão na ação, um projeto em curso, pois a práxis consiste essencialmente em integrar a reflexão e a ação, que, assim, se alimentam mutuamente.

Crítica Social: inspirada no campo da teoria crítica das ciências sociais, integrante também do campo da educação, faz uma crítica ao sistema social e, por consequência, ao sistema socioambiental.

Feminista: esta corrente surge através de movimentos que buscam a análise e denúncia das relações de poder entre os grupos sociais, especialmente ao que se refere no poder exercido dos homens sobre as mulheres, integrando a perspectiva feminista ao modo de governo, produção-consumo, organização social e construção de uma relação harmoniosa dos seres humanos com o meio.

Etnográfica: enfatiza o caráter cultural das relações dos seres humanos com o meio ambiente, impondo uma visão de mundo, considerando sempre a cultura de referência ou comunidades envolvidas no processo.

Ecoeducação: é a perspectiva educacional da educação ambiental, tem o meio ambiente como potencial educativo para o desenvolvimento pessoal, para o fundamento de um atuar significativo e responsável. O meio ambiente é percebido aqui como uma esfera de interação essencial para a ecoformação ou para a ecoontogênese.

Sustentabilidade: tem foco na utilização racional dos recursos naturais, integrando as preocupações sociais e econômicas no tratamento das problemáticas ambientais, sendo que a educação para o desenvolvimento sustentável permitiria atenuar ou solucionar esta carência.

Além das correntes construídas por Sauvé (2005a), percebeu-se na análise dos TCCs, que alguns trabalhos traziam algumas especificidades, sendo que acreditamos que ficariam melhor classificados se criássemos correntes específicas. Deste modo, criou-se duas correntes para enquadrar os trabalhos realizados, a saber: 
Educação Ambiental Escolar: esta corrente refere-se basicamente a tudo o que ocorre dentro da escola, a práxis da Educação Ambiental na escola, em sala de aula ou sobre os métodos utilizados pelos docentes na escola pública (anos iniciais, ensino fundamental e médio), refletindo uma preocupação da constituição da dimensão ambiental da educação escolar (CARNEIRO; DICKMANN, 2016).

Cartográfica ou Diagnóstica: esta corrente refere-se basicamente aos trabalhos na direção de conhecer a percepção, concepções e representações que as pessoas têm a respeito do tema Educação Ambiental. Os trabalhos nessa linha preocuparam-se com diagnósticos e manifestações dos estudantes e professores sobre as questões socioambientais (REIGOTA, 1995; TUAN, 1980).

Para a construção de todas essas correntes e seus estudos, foram necessários esforços e principalmente estudo de professores e pesquisadores, os quais inquietos com a realidade existente, buscaram caminhos para a construção de novas ferramentas na luta contra os males causados à natureza, principalmente buscaram caminhos os quais a sociedade pode seguir para uma perspectiva de qualidade de vida melhor, frente a uma sociedade extremamente capitalista e consumista, sendo assim, a seguir, destacaremos a importância destes profissionais em sua formação no curso de ciências biológicas, onde acima de tudo são cidadãos, que buscam cada dia salvar nosso planeta (ARAÚJO, 2008).

\section{Docente de Ciências Biológicas}

É oportuno repensar a prática pedagógica do professor, no sentido de buscar a construção de um professor reflexivo, que mantém relação de envolvimento com sua prática, que contribui no debate social sobre as intenções e finalidade do processo educativo escolar, ou seja, sobre o papel da escola na sociedade. Com isso, Alarcão (1996, p.176) contribui afirmando que:

Os professores desempenham um importante papel na produção e estruturação do conhecimento pedagógico porque refletem, de uma forma situada, na e sobre a interação que se gera entre o conhecimento científico [...] e a sua aquisição pelo aluno, refletem na e sobre a interação entre a pessoa do professor e a pessoa do aluno, entre a instituição escola e a sociedade em geral. Desta forma têm um papel ativo na educação e não um papel meramente técnico que se reduza à execução de normas e receitas ou à aplicação de teorias exteriores à sua própria comunidade profissional. 
O conceito de "educar para a vida" começa a se difundir, iniciando-se então uma preocupação em relação às verdadeiras necessidades da pessoa como ser global que deve responder aos problemas socioambientais que lhe apresenta a vida em sociedade (SOUSA, 2007).

Dentre as competências do docente de ciências biológicas podem se destacar: a) Pautar-se por princípios da ética democrática: responsabilidade social e ambiental, dignidade humana, direito à vida, justiça, respeito mútuo, participação, responsabilidade, diálogo e solidariedade; b) Reconhecer formas de discriminação racial, social, de gênero, etc. que se fundem inclusive em alegados pressupostos biológicos, posicionando-se diante delas de forma crítica, com respaldo em pressupostos epistemológicos coerentes e na bibliografia de referência; c) Atuar em pesquisa básica e aplicada nas diferentes áreas das Ciências Biológicas, comprometendo-se com a divulgação dos resultados das pesquisas em veículos adequados para ampliar a difusão e ampliação do conhecimento; d) Portar-se como educador, consciente de seu papel na formação de cidadãos, inclusive na perspectiva sócio-ambiental; e) utilizar o conhecimento sobre organização, gestão e financiamento da pesquisa e sobre a legislação e políticas públicas referentes à área; f) Entender o processo histórico de produção do conhecimento das ciências biológicas referente a conceitos/princípios/teorias; g) Estabelecer relações entre ciência, tecnologia e sociedade; h) Aplicar a metodologia científica para o planejamento, gerenciamento e execução de processos e técnicas visando o desenvolvimento de projetos, perícias, consultorias, emissão de laudos, pareceres etc. em diferentes contextos; i) Utilizar os conhecimentos das ciências biológicas para compreender e transformar o contexto sócio-político e as relações nas quais está inserida a prática profissional, conhecendo a legislação pertinente; j) desenvolver ações estratégicas capazes de ampliar e aperfeiçoar as formas de atuação profissional, preparando-se para a inserção no mercado de trabalho em contínua transformação; k) Orientar escolhas e decisões em valores e pressupostos metodológicos alinhados com a democracia, com o respeito à diversidade étnica e cultural, às culturas autóctones e à biodiversidade; 1) atuar multi e interdisciplinarmente, interagindo com diferentes especialidades e diversos profissionais, de modo a estar preparado a contínua mudança do mundo produtivo; m) avaliar o impacto potencial ou real de novos conhecimentos/tecnologias/serviços e produtos resultantes da atividade profissional, considerando os aspectos éticos, sociais e epistemológicos; $n$ ) 
comprometer-se com o desenvolvimento profissional constante, assumindo uma postura de flexibilidade e disponibilidade para mudanças contínuas, esclarecido quanto às opções sindicais e corporativas inerentes ao exercício profissional (BRASIL, 2001, p. 03-04).

Tendo em vista que grande parte dos conhecimentos de ciência já se faz presente nas experiências dos educandos de modo assistemático, o ensino na disciplina de Ciências deve ser aliado à vivência dos educandos, e o enfoque interdisciplinar e problemático passa a ser à base do ensino (SOUSA, 2007).

$\mathrm{Na}$ perspectiva de formação para a cidadania crítica do educando do professor deve atuar de maneira intelectual transformadora, sendo para isso um professor que constrói o próprio conhecimento. Para isso, o professor deve tornar-se um pesquisador. Pesquisar é um ato cognitivo, porque ele nos ensina a pensar num nível mais elevado (KINCHELOE, 1997, p. 179 apud ARAÚJO, 2008).

Para este tipo de docente, faz-se necessário a intensa entrega ao meio de investigação e transmissão de conhecimento, onde, a troca de seu saber com os demais, leva a um nível de discussão intelecto transformador. O saber, o conhecimento por si só não contribui se ele não estiver aberto a novos meios de pensar, meios estes que são na maior parte construído em conjunto (ARAUJO, 2008).

\section{O Curso de Ciências Biológicas da Unochapecó}

O curso de Ciências Biológicas da Unochapecó teve sua fundação no ano de 1992. A Unochapecó está localizada em Chapecó/SC. Sua mantenedora é a Fundação Universitária do Desenvolvimento do Oeste (Fundeste), a área de atuação é a de Ciências Exatas e Ambientais e tem como modalidade a licenciatura - oito semestres; e bacharelado - nove semestres (UNOCHAPECÓ, 2016b).

\footnotetext{
O curso conta com uma estrutura de 14 laboratórios, além de Museu Ciências Naturais e Viveiro Florestal, que servem para trabalhos com Educação Ambiental. Além das aulas em laboratórios, os acadêmicos participam de congressos e palestras como Encibio (Encontro Regional sobre o Ensino em Ciências e Biologia), Congresso Nacional de Zoologia, bem como da Jornada de Estudos Ambientais, realizada anualmente na Unochapecó (UNOCHAPECÓ, 2016b).
}

A Universidade apresenta em seu Projeto Pedagógico uma proposta onde "procura proporcionar aos profissionais não apenas a oportunidade de uma formação 
sólida dos conceitos, princípios e teorias da biologia, mas, ao mesmo tempo, o conhecimento teórico metodológico específico das questões ligadas à área ambiental" (UNOCHAPECÓ, 2007).

\section{METODOLOGIA}

\section{Tipo de Pesquisa}

Para o desenvolvimento deste estudo se utilizou um tipo de pesquisa qualitativa e exploratória, com o objetivo de demonstrar as correntes da Educação Ambiental nos trabalhos analisados. Assim, como pesquisa documental (SÁ-SILVA et al, 2009) tem como base de dados os TCCs do curso de licenciatura em Ciências Biológicas, que será investigado via análise de conteúdo utilizando a metodologia proposta por Bardin (2009).

\section{População e Amostra}

A pesquisa teve como base os TCCs da Unochapecó, desde 1996 até 2015. Com o interesse de buscar os dados dos TCCs da licenciatura em Ciências Biológicas fez-se um contato com a coordenação do curso para obter as informações de todos os formandos. Após receber uma tabela com os dados solicitados, foram separados entre os da licenciatura e do bacharelado. Na sequência foi analisado, tomando como referência, o título de cada trabalho para saber se se tratava de temática ambiental ou não. Desse primeiro levantamento resultou 60 TCCs, os quais foram analisados a partir da leitura do título, do resumo e das palavras-chave, neste procedimento 30 trabalhos foram descartados. ${ }^{5}$ Dos 30 trabalhos restantes, procedeu-se com o fichamento a partir dos dados on line disponíveis na biblioteca da Unochapecó e também de alguns trabalhos com cópia física, pois não estavam digitalizados. Essas fichas continham o nome dos estudantes do curso de ciências biológicas, o nome do orientador, o ano de publicação, título do trabalho, resumo e palavras chave. As fichas construídas de cada TCC serviram para análise e enquadramento dentro das respectivas correntes de Educação Ambiental.

Para análise foram utilizados trinta TCCs, estes estão classificados e demonstrados dentro da corrente pertencente, de acordo com o tema trabalhado e o

\footnotetext{
${ }^{5}$ A opção por verificar somente esses três dados de cada TCC (título, resumo e palavras-chave) está embasada na perspectiva de que ao produzir ciência, quem pesquisa expõe de forma sintética as suas descobertas, bem como seu foco de estudo, dentro desses três itens.
} 
assunto abordado nos TCCs, assim sendo, a primeira coluna, demonstra a corrente de Educação Ambiental e, ao lado, o título do TCC. A importância deste trabalho é demonstrada principalmente, quando as análises dos TCCs incluídos na pesquisa, demonstram temas em educação ambiental desenvolvidos em escolas. E, conforme Tabela 1, ficaram assim subdivididas:

TABELA 1: DIVISÃO DOS TCCs EM CORRENTE DE EDUCAÇÃO AMBIENTAL

\begin{tabular}{|c|c|}
\hline Corrente de EA & Título do TCC \\
\hline Resolutiva & $\begin{array}{l}\text { - A abordagem do lixo no ensino fundamental da escola de educação } \\
\text { básica Pedro Maciel } \\
\text { - Campanha de reciclagem de lixo na escola de educação básica Cardeal } \\
\text { Arco verde } \\
\text { - A abordagem do tema água na educação de jovens e adultos }\end{array}$ \\
\hline Científica & $\begin{array}{l}\text { - O que há no fundo de um lago? A interpretação ambiental através de } \\
\text { bioindicadores bentônicos } \\
\text { - Concepção de educação ambiental dos alunos da } 8^{\circ} \text { Série das escolas } \\
\text { da zona urbana e rural, nos municípios de São Carlos e Xaxim-SC }\end{array}$ \\
\hline Holística & - A trilha dos sentidos e o conceito de meio ambiente \\
\hline Etnográfica & $\begin{array}{l}\text { - Concepções ambientais dos alunos de ensino fundamental e médio da } \\
\text { reserva Kaingáng Xapecó }\end{array}$ \\
\hline Ecoeducação & $\begin{array}{l}\text { - O uso de filmes e recursos didático alternativo na educação ambiental } \\
\text { - Grupo de educação ambiental (GEA) na escola de educação básica } \\
\text { - Coronel Lara Ribas-Estratégias e desafios (um estudo de caso) } \\
\text { A transversalidade da educação ambiental na escola de educação } \\
\text { básica Victor Meirelles }\end{array}$ \\
\hline Sustentabilidade & $\begin{array}{l}\text { - Educação ambiental realizada por supermercados da região Oeste de } \\
\text { Santa Catarina } \\
\text { - O desenvolvimento sustentável na visão de uma escola do meio rural }\end{array}$ \\
\hline $\begin{array}{l}\text { Conservacionista } \\
\text { Recursista }\end{array}$ & $\begin{array}{l}\text { - O potencial do projeto "Natureza, saúde e bem-estar" na promoção de } \\
\text { hábitos de vida saudável e conservação ambiental } \\
\text { - Educação ambiental com ênfase na conservação do lajeado São José } \\
\text { em escolas de Chapecó, Santa Catarina } \\
\text { - O uso de atividades lúdicas com bioindicadores de qualidade de água: } \\
\text { Subsídio para educação e conservação ambiental }\end{array}$ \\
\hline $\begin{array}{l}\text { Educação ambiental } \\
\text { escolar }\end{array}$ & $\begin{array}{l}\text { - Metodologia que os docentes utilizam para trabalhar a educação } \\
\text { - } \quad \text { Educaçação amb } 5^{\circ} \text { Série em escolas de Chapecó-SC } \\
\text { - Representaçãa nas escolas públicas: Realidade e desafios } \\
\text { - } \quad \text { Abordagem da educação ambiente no ensino fundamental nos anos inicias em três escolas do } \\
\text { município de Palmitos } \\
\text { - Educação ambiental no ensino Médio, em uma escola do Nordeste do } \\
\text { Rio Grande do Sul } \\
\text { - Educação ambiental na escola de educação básica Raimundo Corrêa, } \\
\text { Seara-SC }\end{array}$ \\
\hline $\begin{array}{l}\text { Cartográfica ou } \\
\text { diagnóstica }\end{array}$ & $\begin{array}{l}\text { - } \quad \text { Concepção de professores do ensino médio e fundamental do } \\
\text { município de Cunha Porã-SC, sobre educação ambiental } \\
\text { - } \quad \text { A percepção de Meio ambiente dos estudantes com síndrome de Down } \\
\text { - Transversalidade da educação ambiental através dos resíduos sólidos } \\
\text { no ensino fundamental na escola básica municipal Vila Páscoa e } \\
\text { Chapecó-SC } \\
\text { - Diagnóstico dos programas de educação ambiental desenvolvidos em } \\
\text { escolas estaduais da área urbana do município de Palmitos-SC }\end{array}$ \\
\hline
\end{tabular}




\begin{tabular}{|l|l|}
\hline$\bullet$ & $\begin{array}{l}\text { Um olhar de quem olha: A representação ambiental de educadores } \\
\text { ambientais }\end{array}$ \\
$\bullet$ & $\begin{array}{l}\text { Percepção ambiental da comunidade do entorno de unidade de } \\
\text { conservação do Oeste Catarinense }\end{array}$ \\
$\bullet$ & $\begin{array}{l}\text { As práticas educativas sobre educação ambiental e as manifestações } \\
\text { dos alunos do ensino médio }\end{array}$ \\
$\bullet$ & $\begin{array}{l}\text { A abordagem da educação ambiental na escola de educação básica } \\
\text { Professora Jurema Savi, Quilombo-SC } \\
\text { Métodos utilizados para a abordagem da educação ambiental nas } \\
\text { escolas estaduais de Chapecó-SC }\end{array}$ \\
\hline
\end{tabular}
Fonte: Elaboração dos autores com base em Sauvé (2005a) e ampliação das duas últimas correntes.

A Figura1 demonstra através de um gráfico com a quantificação dos trabalhos de conclusão de curso, de acordo com a corrente pertencente dentro do tema trabalhado neles.

FIGURA 1 - QUANTIFICAÇÃO DOS TCCs EM SUAS RESPECTIVAS CORRENTES

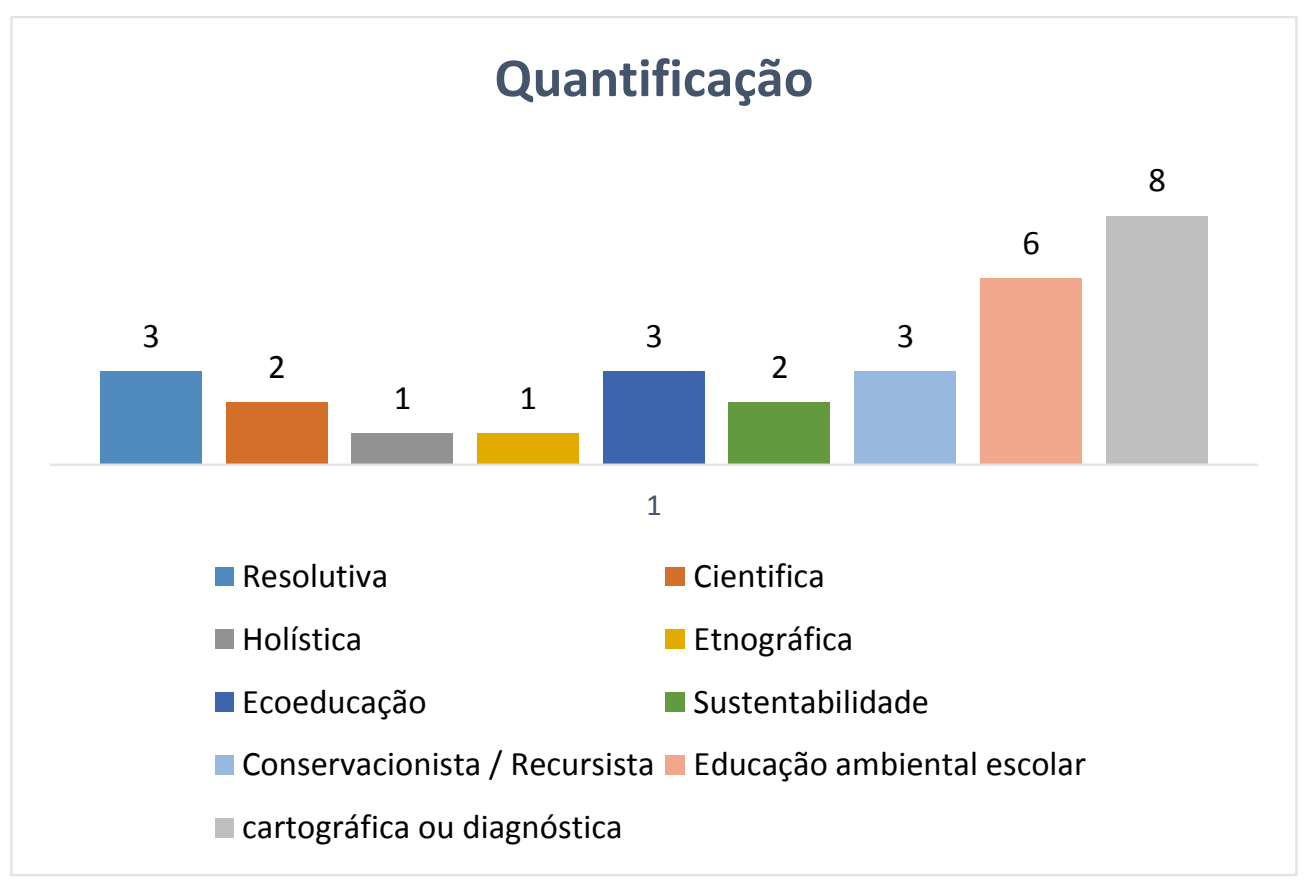

Fonte: elaboração dos autores (2017)

Como demonstrado na Figura 1, a maior corrente ambiental representada durante os anos de 1993 a 2015 foi a corrente cartográfica/diagnóstica, com oito trabalhos de conclusão de curso, dos quais somente dois não tiveram o tema trabalhado com a Educação Ambiental em escolas ou com alunos. Em seguida, vem a corrente de Educação Ambiental Escolar, a qual apresentou seis TCCs, onde todos os temas abordados foram desenvolvidos em escolas e com alunos; logo vem a corrente 
conservacionista/recursista com três TCCs, dos quais, um teve o tema desenvolvido em escolas. Também, com três TCCs, temos a corrente resolutiva, onde todos os temas foram desenvolvidos com escolas e alunos. A corrente de Ecoeducação, também apresentou três trabalhos, e destes, dois foram trabalhados com temas em Educação Ambiental diretamente ligados a escolas e seus educandos, e um com o tema desenvolvido com professores. Também obtivemos as correntes sustentabilidade e científica com dois TCCs cada, com trabalhos nas áreas urbana e rural. Por fim, temos a corrente etnográfica com um trabalho de conclusão de curso, onde seu tema foi desenvolvido em uma escola, e a corrente holística com um trabalho também, porém, este teve como tema a percepção da educação ambiental na sociedade em geral.

\section{DISCUSSÃO E RESULTADOS}

Com a análise, ainda se constatou, que a maioria dos temas foram desenvolvidos com o ensino fundamental, onde os alunos têm o primeiro contato com o tema, sendo assim, é de importante que a Educação Ambiental seja abordada nas escolas, para demonstrar o esgotamento do atual modelo de produção e consumo, que cria mais problemas socioambientais que soluções para uma vida sustentável (LIMA, 1999).

A formação de docentes e pesquisadores com formação em Educação Ambiental é válido, quando nos deparamos com um mundo voltado para o capitalismo, materialismo e produção em massa, quando, vivemos em um planeta em que a maior parte da população não tem ações e atitudes voltadas para a proteção e cuidado do meio em que vivem.

A maneira de pensar em um meio ambiente mais saudável, e em Educação Ambiental, deve-se transcender uma utopia, e passar a estar em atitudes no dia a dia das famílias, pois muitos, até ouvem a respeito do tema, porém, pensar e agir de uma maneira consciente e respeitadora frente à natureza está bem longe da realidade da maior parte das famílias.

Com a inclusão do tema, e explorando a Educação Ambiental através de suas diversas correntes, desde as séries iniciais nas escolas, os docentes devidamente especializados a trabalhar com este tema, poderão torná-lo familiar aos educandos, desenvolvendo-o de uma maneira gradativa e integradora com o meio em que vivem, demonstrando a sua diversidade de compreensões de mundo, de meio ambiente e de abordagem da Educação Ambiental (BERTOLUCCI et al, 2005). 
Um fator importante é a oferta e frequência de disciplinas que abordem a Educação Ambiental e suas correntes dentro do currículo do curso de Ciências Biológicas, na duração do curso; este é um fator que vem a contribuir para a construção de um profissional consciente do seu papel frente a sua docência. Os currículos devem abranger meios que façam seus alunos tomarem atitude frente aos problemas ambientais, sendo capazes de modificar seu meio e preocupando-se com as gerações futuras.

Profissionais capacitados e cheios de vontade de modificar a realidade ambiental de nossa sociedade terão mais ferramentas para desenvolver o tema nas escolas, com diferentes formas, poderão apresentar o tema com mais conhecimento, podendo não somente debater uma forma sustentável para lidarmos com o meio ambiente, mas sim podendo explorar as diversas correntes dentro em Educação Ambiental.

Para que nosso planeta tenha esperança de modificação do ser humano em suas atitudes, tanto dentro do ensino fundamental, médio e superior faz-se necessário a formação de um educando-cidadão, e o responsável por esta formação é a trajetória do educador, onde através de diversos caminhos pode abordar o tema educação ambiental em sala de aula, trazendo para o ambiente escolar as experiências vivenciadas pelos sujeitos, no meio em que vivem, e problematizando-os como temas geradores na Educação Ambiental (TOZONI-REIS, 2006).

\section{CONSIDERAÇÕES FINAIS}

O principal ponto a ser considerado a respeito dos autores aqui trabalhados, é a importância do tema Educação Ambiental ser abordado em escolas, contemplando os educandos, das séries iniciais até o ensino médio e depois se transformando em objeto de pesquisa nos cursos de graduação e pós-graduação. Há uma preocupação que o formando tenha um aprofundamento no tema de forma privilegiada em sala de aula, motivando-o para que ele esteja sempre em busca do conhecimento.

As mudanças no clima vivenciadas nos dias de hoje, nos levam a pensar que é necessário educar a sociedade para não precisar corrigir depois os erros, pois, nossos atos frente à natureza não permitem correções, todos os atos têm uma consequência, e na maioria das vezes sofremos consequências graves, por atitudes que tomamos no dia a dia. 
Muitas atitudes tomadas no cotidiano passam despercebidas, sem nos darmos conta que estamos errados, e que não estamos só prejudicando o meio ambiente, mas sim a nós mesmos, nós seres humanos, seres pertencentes à natureza, que muitas vezes acreditam estar fora do mundo e de suas regras naturais. O ser humano acredita estar blindado sobre suas invenções, as quais, nunca conseguem evitar catástrofes da natureza, nem minimizar, na maior parte os danos nocivos ao nosso corpo decorrente da poluição.

Como a sociedade vem sofrendo transformações e estabelecendo novas relações sociais em suas diversas estruturas, exige-se da escola a formação de um novo educando-cidadão, o qual seja capaz de atuar na sociedade de maneira transformadora.

Este trabalho pode deixar como principal contribuição a importância do estudo das correntes em educação ambiental, principalmente no currículo do curso de Ciências Biológicas, o qual é a uma porta onde saem muitos educadores, os quais detêm o papel de construção/reflexão, principalmente, dos conhecimentos adquiridos na universidade. Sendo assim, podemos afirmar que a educação ambiental é uma educação para a cidadania, buscando formar cidadãos críticos sobre a realidade do seu entorno e cabe aos egressos das licenciaturas em Ciências Biológicas se comprometerem com essa tarefa de contribuir na conscientização dos sujeitos. A formação cidadã vem sendo destacada como necessária, para que os cidadãos possam contribuir na construção de novos valores, para isso, a escola e o professor devem ter capacidade intelectual e de pesquisa, para que se possam construir conhecimentos pautados em vista do bem mútuo.

Dado o exposto até aqui, percebemos que é indiscutível e necessário repensar a prática pedagógica do professor, buscando um professor reflexivo que mantenha um envolvimento contributivo "no debate social sobre as intenções e finalidade do processo educativo escolar, ou seja, sobre o papel da escola na sociedade". Se as universidades se aliarem com professores comprometidos, e realizarem seu papel cidadão em sociedade, provavelmente muito mais poderá ser feito em relação à maneira de disseminação do conhecimento, referente às diferentes correntes ambientais, principalmente, fazendo com que elas não fiquem somente como boas ideias, mas sim, que eles possam se transformar atitudes no dia a dia da sociedade, tendo em vista a dimensão da formação integral dos sujeitos-educandos na perspectiva da cidadania planetária. 


\section{REFERÊNCIAS}

ALARCÃO, I. Formação reflexiva de professores: estratégias de supervisão. Porto/Portugal: Porto Editora, 1996.

ARROYO, M. Os momentos sociais e a construção de outros currículos. Educar em Revista, Curitiba, n.55, p.47-68, jan./mar, 2015.

ARAÚJO, O. J. M. Professores intelectuais transformadores e a formação do aluno cidadão crítico. 2008. Disponível em: http://www.webartigos.com/artigos/professoresintelectuais-transformadores-e-a-formacao-do-aluno-cidadao-critico/12433/.

BARDIN, L. Análise de conteúdo. Lisboa: Edições 70, 2009.

BERTOLUCCI, D. et al. Educação Ambiental ou Educações Ambientais? As adjetivações da educação ambiental brasileira. REMEA, Rio Grande, v. 15, jul./dez. p. 36-48, 2005.

BRASIL. Diretrizes Curriculares Nacionais para os Cursos de Ciências Biológicas. Parecer CNE/CES 1.301/2001. 2001.

BRAYNER, M. de F. M. Educação ambiental e cidadania. In: ELIAS, M. D. C. (Org.). Pedagogia Freinet: teoria e prática. Campinas: Papirus, 1996. p. 143-150.

CARNEIRO, S. M. M.; DICKMANN, I. Educação Ambiental na escola a partir de Paulo Freire. In: HAGEMEYER, R. C. C.; SÁ, R. A.; GABARDO, C. V. (Orgs.). Diálogos epistemológicos e culturais. Curitiba: W\&A, 2016.p. 233-254.

CASCINO, F. Educação Ambiental: eixos teóricos para uma reflexão curricular. In: CASCINO, F.; OLIVEIRA, J. F.; JACOBI, P. (Orgs.). Educação, meio ambiente e cidadania: reflexões e experiências.São Paulo: Secretaria de Meio Ambiente, 1998. p. $15-22$.

DEMO, P. Metodologia da investigação em educação. Curitiba: IBPEX, 2005.

DICKMANN, I.; CARNEIRO, S. M. M. Paulo Freire e Educação ambiental: contribuições a partir da obra Pedagogia da Autonomia. Revista de Educação Pública, Cuiabá, v. 21, n. 45, p. 87-102, jan./abr, 2012.

DICKMANN, I; HENRIQUE, L. Formação inicial de educadores ambientais: desafios, limites e avanços. Revista de Educação Pública, Cuiabá, v. 26, n. 63, p. 839-853, set./dez. 2017.

DICKMANN, I. Percepção ambiental e leitura de mundo: uma abordagem freiriana.In: VENDRUSCOLO, G. S; CONFORTIN, A. C.; DICKMANN, I. (Orgs.). Percepção de meio ambiente: o que pensam as pessoas sobre o seu entorno?São Paulo: Ação Cultural, 2016. p. 11-23.

DIEGUES, A. C.O mito moderno da natureza intocada. 3. ed. São Paulo: Hucitec, 2001.

GADOTTI, M. Pedagogia da Terra. 6 ed. São Paulo: Pierópolis, 2009. 
HÖEFFEL, J. L. V.; VIANA, R. M.; PADUA, S. M. A Consciência Ambiental e os 5 "ES". In: CASCINO, F.; OLIVEIRA, J. F.; JACOBI, P. (Orgs.). Educação, meio ambiente e cidadania: reflexões e Experiências.São Paulo: Secretaria de Meio Ambiente, 1998. p. 23-25.

IARED, V. G.; VALENTI, M. W.; MARPICA, N. S.; LOGAREZZI, A. J. M.; OLIVEIRA, H. T. Coexistência de diferentes tendências em análises de concepções de educação ambiental. REMEA, Rio Grande, v. 27, jul./dez, 2011.

JACOBI, P. Educação ambiental e Cidadania. In: CASCINO, F.; OLIVEIRA, J. F.; JACOBI, P. (Orgs.). Educação, meio ambiente e cidadania: reflexões e experiências.São Paulo: Secretaria de Meio Ambiente, 1998. p.11-14.

LAYRARGUES; P. P.; LIMA, G. F. C. As macrotendências político-pedagógicas da educação ambiental brasileira. Ambiente e Sociedade, São Paulo, v. XVII, n. 1, p. 23 40, 2014.

LIMA, G. F. C. Questão ambiental e educação: contribuições para o debate. Ambiente \& Sociedade, Campinas, ano II, n. 5, 135-153, 1999.

LOUREIRO, C. F. B. Trajetórias e fundamentos da educação ambiental. 3 ed. São Paulo: Cortez, 2009.

REIGOTA, M. Meio ambiente e representação social. São Paulo: Cortez, 1995.

REIS, M. et al. A educação ambiental na formação inicial de professores de biologia: concepções, componentes curriculares e possibilidades de ações segundo os licenciandos. Ensino, Saúde e Ambiente, v. 6, n. 3, p. 96-113, 2013.

ROMÃO, J. E. Pesquisa na Instituição de Ensino Superior: referencial teórico, que bicho é este? Cadernos de Pós-Graduação, São Paulo, v. 4, p. 19-32, 2005.

SÁ-SILVA, J. R.; ALMEIDA, C. D.; GUINDANI, J. F. Pesquisa documental: pistas teóricas e metodológicas. Revista Brasileira de História \& Ciências Sociais, Ano 1, n. 1, julho, 2009.

SABIÁ, I. R. A Escola e a Educação Ambiental: Relato de Experiências. In: CASCINO, F.; OLIVEIRA, J. F.; JACOBI, P. (Orgs.). Educação, meio ambiente e cidadania: reflexões e experiências. São Paulo: Secretaria de Meio Ambiente, 1998.p.35-37.

SAUVÉ, L. Uma cartografia das correntes em Educação Ambiental. In: SATO, M.; CARVALHO, I. C. M. (Orgs.). Educação Ambiental: pesquisa e desafios. Porto Alegre: Artmed, p. 17-44. 2005a.

SAUVÉ, L. Educação Ambiental: possibilidades e limitações. Educação e Pesquisa, São Paulo, v. 31, n. 2, p. 317-322, maio/ago, 2005b.

SOUSA, J. D. R. A prática pedagógica do professor de ciências e sua contribuição para a formação de cidadãos na sociedade contemporânea. 2007. Disponível em: http://leg.ufpi.br/subsiteFiles/ppged/arquivos/files/eventos/evento2004/GT14/GT2.PDF.

SOUZA, V. M. Para o mercado ou para a cidadania? A educação ambiental nas instituições públicas de ensino superior do Brasil. Revista Brasileira de Educação, v. 21 n. 64, 2016. 
SPAREMBERGER, R. F. L.; SILVA, D. A. A relação homem, meio ambiente, desenvolvimento e o papel do direito ambiental. Veredas do Direito, v. 2, n 4, p. 81-99, jul/dez. 2005.

STRECK, D. R. A pesquisa em educação na Região Sul: percursos e tendências. Educação, Porto Alegre, v. 38, n. 2, p. 263-271, maio/ago. 2015. DOI: http://dx.doi.org/10.15448/1981-2582.2015.2.19658

TOZONI-REIS, M. F. C. Temas ambientais como "temas geradores": contribuições para uma metodologia educativa ambiental crítica, transformadora e emancipatória. Educar em Revista. Curitiba, n. 27, p. 93-110, jan./jun. 2006.

TUAN, Y. Topofilia: um estudo da percepção, atitudes e valores do meio ambiente. São Paulo: Difel. 1980.

UNOCHAPECÓ. Universidade Comunitária da Região de Chapecó. Síntese do projeto pedagógico do curso de graduação em ciências biológicas (bacharelado). 2007. Disponível em:https: //www.unochapeco.edu.br/static/data/portal/sites/ppc/38.pdf.

UNOCHAPECÓ. Universidade Comunitária da Região de Chapecó. Projeto pedagógico de curso-PPC. 2016a. Disponível em: https://www.unochapeco.edu.br/.

UNOCHAPECÓ. Universidade Comunitária da Região de Chapecó.O curso. 2016 b. Disponível em: https://www.unochapeco.edu.br/biologia/o-curso 